Multi-Media Session 2793

\title{
IMPROVING THE ENGINEERING AND WRITING INTERFACE: AN ASSESSMENT OF A TEAM-TAUGHT INTEGRATED COURSE
}

\author{
Roberta Harvey ${ }^{1}$, Frances S. Johnson ${ }^{1}$, Heidi L. Newell ${ }^{2}$, Kevin Dahm ${ }^{2}$, Anthony J. \\ Marchese $^{2}$, Ravi P. Ramachandran ${ }^{2}$, John L. Schmalzel ${ }^{2}$, \\ Carlos Sun ${ }^{2}$, and Paris von Lockette ${ }^{2}$

\section{College of Communication, Rowan University, Glassboro, New Jersey} \\ 2. College of Engineering, Rowan University, Glassboro, New Jersey
}

\begin{abstract}
This paper presents the results of a preliminary investigation into second-year engineering students' attitudes towards writing. Our study assesses what effect, if any, the presence of engineering faculty as part of a teaching team has on students' perceptions of the importance of writing to engineering and the overall quality of student writing. Sophomore Engineering Clinic I, planned and taught by faculty from the College of Communication and the College of Engineering, combines argumentative discourse, technical communication, and engineering design labs. While the course is jointly planned, it had previously been individually delivered. Worth four credits, three credits were devoted to writing and one to engineering design. As part of the present study, engineering faculty are attending 2 of the 4 writing sections. They actively join in class discussions, assist in peer critiques, ask questions, seek clarifications, and provide real life engineering examples. The remaining 2 sections are taught solely by Communication faculty. We suspect that engineering students allocate more time to their design projects, even though the writing assignments are more heavily weighted. We also suspect that students do not see connections between engineering problem solving and writing problem solving. Rather, they see writing as an ancillary tool that follows the "real" work of engineering. To test these assumptions, a survey was administered to all sections of the course. The survey asks a range of questions about the amount of time, effort, and revision the students usually apply to writing assignments. At the end of the term, the survey will be given again and results will be analyzed for significant patterns and measurable shifts. In addition to the survey, all faculty are keeping a log of classroom observations. Logs detail events and activities, as well as the students' responses, in all sections, and will provide a qualitative context for the survey results. Our findings will be used to conceptualize the teaching and learning interactions that materialize in a teamteaching situation, to develop future directions for assessment of the value of teamteaching, and to determine whether this direct form of team-teaching should be pursued further.
\end{abstract}

\section{History and Background of the Rowan Engineering and College Writing Partnership}

In 1992, industrialist Henry Rowan made a $\$ 100,000,000$ donation to then Glassboro State College to establish a high-quality engineering school in southern New 
Jersey. This gift has enabled the university to create an innovative and forward-looking engineering program. The College of Engineering at what is now Rowan University is comprised of four programs: Chemical, Civil and Environmental, Electrical and Computer, and Mechanical. Each program serves 15 to 35 students per year, resulting in 60 to 140 students per year in the College. The size of the College has been optimized such that it is large enough to provide specialization in separate and credible programs, yet small enough to permit a truly multidisciplinary curriculum in which laboratory/design courses are offered simultaneously to all engineering students in all four disciplines [1].

The hallmark of the Rowan engineering program is the multidisciplinary, projectoriented Engineering Clinic sequence and its emphasis on technical communication. The Clinics are taken each semester by every student. In the Engineering Clinic, modeled after the medical school concept, students and faculty from all four engineering programs work side-by-side on laboratory experiments, real-world design projects, and research. The solutions of these problems require not only proficiency in the technical principles, but as importantly, require effective written and oral communication skills and collaborative abilities [1]. The Sophomore Engineering Clinics specifically serve the dual purpose of introducing students to formalized engineering design techniques and providing them with the necessary foundation for their careers as technical communicators. In order to achieve both of its key goals and meet university-wide general requirements, Sophomore Engineering Clinics are team-taught by faculty from the College of Engineering and the College of Communication [2]. This paper will focus on Sophomore Engineering Clinic I, which integrates the engineering clinic with a specialized version of the required second semester composition course. (Sophomore Clinic II incorporates a public speaking component.)

From the inception of the program four years ago, it was agreed that the writing course would be designed to meet the needs of both colleges, Communication and Engineering, and the students' needs as well. As a General Education requirement, the course also had to meet the demands of department and university curriculum committee guidelines. This process involved reshaping a course traditionally based entirely on research and argumentation into a technical writing course that retained a strong research and argumentation emphasis. It was also agreed that the course would be student-centered and challenging. Through the ensuing years, as the course has been tried and tested and adjusted, this emphasis has been one of its major constants. Various permutations of the combined courses have been attempted, with each year another step intended to improve integration between the two disciplines [3].

The courses have been linked since the first planning stages, but disciplinary boundaries and issues of authority and trust often impeded the full integration sought by the team. By and large, engineering and writing sections were collaboratively planned, but run separately. Team meetings provided a place to share and compare assignments that were created by individual instructors. Only one or two assignments could be considered to have been collaboratively developed. These assignments were turned in to both engineering and writing faculty, and received grades from both. Fifty percent of the students' final grades came from the writing professors and the other half from the engineering professors. Although student transcripts recorded a single grade for a 
combined four-credit course, credit and grade points were computed separately for the two components and averaged at the end. Moreover, a student had to pass "both sections" of clinic to receive a passing course grade. While these activities do fit with definitions and models of interdisciplinary teaching, they did not fit with the team's concepts of interdisciplinary teaching [4].

Thus, the means of integrating writing into the engineering curriculum has proven a challenge for us. Asking a member of the writing faculty to assist with grading engineering lab reports, or asking writing faculty to attend oral presentations at the end of the term, does not constitute integration. Furthermore, even a combined, team-taught course does not guarantee integration if lab periods focus solely on engineering projects and lecture periods focus solely on writing assignments [2]. Most importantly, comments received on student evaluations confirm that such integration has not been achieved in the minds of the students. Students see their workload as doubled because they prepare assignments for writing and engineering professors. Students, in fact, resent what they see as an artificial combination of two courses done chiefly for bookkeeping efficacy, that is, as a way to count two courses as one and thereby fit them into an already credit-intensive curriculum. The development of the course has not been seamless from a faculty perspective either. Conflicts are inevitable when two very different disciplines must negotiate a middle ground that preserves the often disparate pedagogical objectives of both [3]. Exacerbating these difficulties was that fact that the need for the course had been mandated; it was driven by "top down" (administrators) rather than "bottom up" (teachers) motives. It is important to note that most of these difficult negotiations took place in the pilot-phase of the course design and also that these discussions consumed one year's worth of energy. However, these initial discussions lead to a more successful course.

To address these problems, the engineering and writing faculty have utilized various strategies for better merging their missions and their instruction. From the start, engineering and communication faculty worked to design a curriculum that would negotiate this middle ground. Engineering faculty have had input into the design of writing assignments just as writing faculty have assisted in refining engineering assignments. The course now reflects the team's challenging negotiations of trust, authority, and disciplinarity. For instance, engineering and writing faculty rethought the purpose of team meetings. Now these meetings are used to review what is happening in the classroom, plan assignments, and discuss broad course planning issues. Faculty make a point of alluding to these discussions in class in order to let students know that such communication and collaboration goes on. The increased integration has had positive results for the faculty too. The engineering and writing faculty have collaborated on a number of conference paper projects, as well as an NSF proposal for instructional resources. Each semester begins with a "kick-off" session where all faculty are introduced to the students and participate in class ice-breaking activities. These practices have done much to bridge disciplinary differences and create opportunities for innovative multidisciplinary teaching to develop [3].

The Fall 1999 version of Sophomore Engineering Clinic I incorporated several new initiatives that achieved some of the most dramatic evolution yet. A number of changes were implemented to move collaboration beyond the level of faculty spirit and 
make it more visible to students. While a syllabus incorporating writing and engineering had always been prepared, the divisions between the disciplines were clear. A single syllabus was developed that covers both components of the course in terms of course description, objectives, logistics, supplies, and other conventional syllabus items. Only specific classroom policies - attendance, late work submission, and the like - were individually articulated by instructors. A single list of course requirements was developed in the form of "technical communication deliverables," which included five assignments turned in only to the writing instructors, but also included two major team-written assignments which serve as the primary output of the semester's engineering work as performed during lab sections. Engineering projects, then, were evaluated largely on the basis of the documents that report design experiments and results. Most grading and credit hour divisions were discarded. In addition, while faculty have always met to report final grades, our meetings now have been recast into what we call our "grading marathon." In this session, each member of the team comes prepared with comments about the projects' successes and failures. Final grades are determined using similar guidelines. Instead of averaging separately determined engineering and writing grades, faculty now discuss student performance and arrive at a holistic grade.

A final change in the structure of the course this semester is the subject of the remainder of this paper. The faculty decided to attempt an even more direct approach to team-teaching by having engineering faculty regularly attend the class periods devoted to writing instruction. During these "visits," engineering faculty were to function not merely as observers but as active participants in classroom activity and instruction. Their role was to contribute their perspectives on matters being discussed in writing lectures and to talk with students while they worked on in-class projects. Further, this new element of the course was used as an occasion to actually measure student attitudes towards writing instruction and to assess whether collaborative teaching would have a positive impact on student perceptions of the importance of writing to engineering, and/or would have a positive impact on the quality of student writing.

\section{Some Preliminary Conceptualizations of Collaborative Teaching Arrangements}

Collaborative teaching can take many forms. A pure team-teaching arrangement would involve a single course with two or more teachers fully sharing preparation and teaching responsibilities. The arrangement under consideration in the present study does not yet approach this ideal model, but it has evolved from a situation in which engineering faculty have assisted writing faculty with course planning to one in which engineering and writing faculty are together in the classroom and both interacting with students. Considering other forms of collaboration can suggest ways of conceptualizing what kinds of relationships and interactions might be the objectives of team-teaching.

Two such variations on collaborative teaching by engineering and writing faculty are described in [5]. Both involved situations where writing faculty were not actually teaching a course, but rather serving as "writing consultants" who were members of English departments but worked in engineering schools. The first example was the focus of a master's thesis study at the University of North Dakota [6]. At the time of the study, a Writing Across the Curriculum (WAC) program was being developed in order to 
formalize writing instruction in the disciplines and move it beyond the traditional composition courses. This particular writing consultant arrangement had, however, been developed independently by the chemical engineering department and had in fact been in place since the 1960s. Under this arrangement, a writing consultant from the English department--usually a graduate teaching assistant--was hired to assist with grading reports and tutoring students for the junior-level laboratory course. The English teacher was originally called an "English grader" and was asked to assign a partial grade to each report based on its grammatical and mechanical correctness. More recently, the English grader evolved into the writing consultant, and there was less concern with restricting the role. Specifically, at the time of this study, this arrangement functioned as follows. The engineering professor used a grading checklist that listed point values for several technical aspects of the reports. The checklist included an item called "English and format," worth 20 of the 100 possible points, to be filled in by the writing consultant who was largely free to design the grading criteria within this portion. Students turned in their reports to the writing consultant first, who commented on and graded the report according to the criteria he or she developed (usually some version of the conventional criteria of organization, style, grammar, and mechanics) and then passed the reports on to the engineering professor. Since the time of the study, the grading process further changed and shifted away from the split grade. Commenting on the reason for the change, the chemical engineering professor who oversaw the arrangement explained that

[the] change in emphasis is motivated by the argument that split grading of the "technical content" by the professor and the "writing mechanics" by the English grader emphasizes and acknowledges that learning in the course is somehow distinct from writing in it. Since this is contrary to the departmental philosophy that clear writing is an indication of clear thinking (and hence good learning) ... [b]oth the professor and the writing consultant grade the entire paper for readability and clarity. [7]

Where engineering and writing faculty had been in the past confined to particular domains and had interacted little with each other, they now began to realize that their domains overlapped. They began to collaborate in their teaching by reading student papers "together," in a manner of speaking.

The study largely focused on the other important duty of the writing consultant, individual conferences with students. Although these conferences did not involve direct team-teaching with the engineering professor, they often did center on a kind of indirect collaboration among faculty, and analysis of the conferences serves to point out certain aspects of the engineering and writing faculty relationship. Students were required to see the writing consultant at least three times, either with drafts or with graded reports. The study found that while the grading arrangement and the written comments on the reports seemed to reflect a rather limited and traditional role for the English teacher, conference conversations exhibited a markedly broader range of concerns, ranging from spelling to the theoretical framework of experiments.

The study characterized the roles assumed by the writing consultant in conferences and the resulting interactions with students in three ways. The first role was as an authority, in which she told students how she wanted something done without giving much explanation of why. Students asked questions about the placement of 
punctuation marks or about stylistic concerns such as sentence structure, and the writing consultant gave straightforward answers.

The other two roles were more prevalent and also more complex. These roles suggest that the writing consultant was in some sense collaborating with the engineering professor. One role was characterized as that of "mediator," when she helped students assess the demands of the engineering professor and of the engineering field itself. This mediation usually took the form of referring to and explaining the various other authorities, including texts, that influenced what was considered to be a good report. For example, during the semester in which observations were conducted, a mild debate arose over the use of the expression "percent error," which both the professor and the writing consultant felt was a slang or short form for "percentage of error." Rather than prescribing a correct usage, the writing consultant suggested several possible authorities that might govern the students' decision: their engineering professor's preference, the usage the students preferred in the lab or in their papers, or the form used in their textbooks. The writing consultant also relayed her understanding of the professor's expectations on matters such as what particular sections of the report should include. She pointed out instructions he had given in handouts or comments he made on other papers. Technical writing texts and handbooks were yet another authority the writing consultant brought into the discussions for students' consideration. These instances were considered to be distinct from her actions in the role of authority because she explicitly told students that certain rules--for example, using figures instead of spelling out numbers--were dictated by style manuals or by technical writing conventions. By pointing out various authorities and supplying advice, she demonstrated to students how to make decisions about their writing. Often, her suggestions were the result of negotiation with the perceived demands of the engineering faculty, another relationship related to collaboration.

The third role was termed the "translator," in which the consultant helped students "translate" relevant physical data or observations into writing. In these situations, students had to decide if certain kinds of information were appropriate or necessary, such as, for example, whether or not a particular procedural step needed to be mentioned or its purpose described. These conversations usually involved the consultant asking the student what they had done or what had happened and then asking if there were reasons why that information should be included. For example, in one conversation she asked a student whether his mention of pressing the "start" button on an instrument was necessary. The student replied that yes, it was important because if the experimenter did not press "start" right away, the results would be affected. The consultant then suggested that the student state this in such a way as to make clear the significance of pressing "start" at that moment. The wording became: "for each one, a sample was injected and start was pressed immediately to ensure the accuracy of the measurement." In this way, the student participated in the process of deciding what to write and how. Again, what the writing consultant had done was to interpret the expectations of the engineering faculty who would be reading the report.

The second example was that of a writing consultant arrangement in the College of Engineering and Applied Science at the University of Wisconsin-Milwaukee [5]. One of the writing consultant's experiences involved a presentation to a civil engineering class 
on how to write laboratory reports. The course was an upper division civil engineering course called Experimental Stress Analysis. The instructor gave the writing consultant a syllabus and samples of "good" student reports to use in developing a presentation. The instructions students had been given by their engineering professor regarding lab reports consisted of the following statement in the syllabus:

Lab reports must be typed and neat and must contain information on the experimental setup, procedure, and results. Lab reports should not be too long. The writing consultant met twice with the engineering professor to discuss what he wanted covered and to have him approve the directions that would be given. A handout with two sections was developed: Format and Organization, which named the sections of a standard lab report and described what each should include; and Aspects of Style, which mentioned some stylistic conventions of report writing and gave examples from the sample student reports. Comments were also included to explain and qualify instructions and mention other authorities--for example:

Remember that this format can and should be altered to best report the experiment. Some sections may be combined and/or headings may be changed. For examples of format variations, look at professional journals such as The Journal of Strain Analysis for Engineering Design, The Journal of Vibration and Acoustics, Applied Surface Science, and WEAR.

The materials for the presentation, which interpreted and expanded on the original guidelines given in the syllabus, were thus a product of collaboration between the writing consultant, the engineering professor, and even the engineering profession itself.

The presentation itself was the more overtly collaborative part of this project. As the handout, reproduced on a transparency, was being discussed by the writing consultant, both the professor and the laboratory assistant made comments on and sometimes additions and revisions to the instructions. These comments were then added to the transparency and made part of the presentation. One particularly interesting moment occurred when the three instructors discussed, in front of the students, how best to handle experimental calculations, which were not addressed in the presentation. The writing consultant offered suggestions, and eventually the professor and the laboratory assistant decided that they wanted to have a sample calculation shown in the Results section, with the rest of the calculations being placed in a separate Appendix section. Another discussion concerned whether it was necessary to have a separate Objectives section or to include a statement that said "the objective of this experiment is . ..." Again, the question was raised in front of the students, who then witnessed how the decision was made. In this case, the professor commented that he did not think the term "objective" needed to appear, but that it was important that the introductory section make clear what the objectives were. Placing objectives in a separate section was deemed optional. The important lesson for students in this particular class was that rules are not universal or transcendental; instead, they are situational and decided on in response to particular needs. They were also able to observe engineering and writing "authorities" pooling their expertise to reach common objectives.

Engineering students often view writing as an unpleasant and ancillary task that is secondary to the real work of engineering. They also often find judgments by writing teachers about the effectiveness of their writing to be idiosyncratic, arbitrary, or simply 
mysterious. The key element of both of the arrangements discussed above is that students are able to witness firsthand the development of writing standards within the context of their discipline. When writing standards are "worked out" by writing and engineering faculty together, whether this working out is direct or indirect, students realize that the attributes of good writing are not idiosyncratic, arbitrary, or mysterious, but rather functional.

\section{Assessment of Current Team-Teaching Arrangement}

The team-teaching arrangement currently being attempted at Rowan is more demanding than the consultant arrangements discussed above in that it requires faculty who already have a full teaching schedule to attend an additional course. For this reason, it could not be treated lightly. Such an arrangement can be formally incorporated into the curriculum only if it is proven to be valuable. To investigate its value, the team-teaching was undertaken in an experimental fashion. Engineering faculty attended two of the four writing sections, while the other two were taught by writing faculty alone. An initial survey of attitudes toward writing was administered in all sections. In addition, all faculty were asked to keep "teaching logs," informal, discursive accounts of and reflections on what went on during class. The logs provide a qualitative context for the survey results. As was done with the collaborative teaching arrangements discussed above, the particular nature of the teaching relationship and its impact on student learning will need to be conceptualized. Students were also asked to fill out a mid-semester evaluation of course objectives and teacher performance, which will also provide comments to assist with interpretation of the surveys. Finally, the initial survey was given again during the final week of the semester. These "exit" responses will be statistically compared with those of the initial survey in order to see if any measurable shifts have occurred.

This assessment is, of course, very rudimentary as well as preliminary. It is hoped that the results will be substantial and meaningful enough to indicate whether this form of team-teaching should be pursued--and if so, to support requests for institutional support-and to suggest more refined methods of assessing its pedagogical consequences.

\section{Preliminary Results of Current Investigation}

\section{4-1. Survey Results}

Survey results will be statistically analyzed once final results are available for comparison. For now, results will be examined for general trends only.

Several questions asked students to rate the degree to which they prioritized writing assignments in terms of time and effort as compared to assignments for engineering courses, required math and science courses, and general education electives. As expected, a majority of students prioritized engineering and math and science courses over writing courses, while prioritizing writing courses over their other non-technical courses. Three other questions more specifically address questions of writing and 
engineering integration. One question, how would you describe your attitude toward writing, simply asked for subjective impressions of the activity of writing:

\begin{tabular}{|l|c|}
\hline How would you describe your attitude towards writing? \\
\hline Answer & Responses (n=85) \\
\hline Avoid if possible & $8.2 \%(7)$ \\
\hline Dislike intensely & $4.7 \%(4)$ \\
\hline Tolerate; do if have to & $64.7 \%(55)$ \\
\hline Do willingly & $12.9 \%(11)$ \\
\hline Enjoy & $9.4 \%(8)$ \\
\hline
\end{tabular}

Another question, how do you think your proficiency as a writer will affect your career as an engineer, was designed to distinguish between the perception that writing is helpful or important to engineering as a secondary tool and the perception that writing is essential to engineering as a primary practice:

\begin{tabular}{|l|c|}
\hline \multicolumn{2}{|l|}{$\begin{array}{l}\text { How do you think your proficiency as a writer will affect } \\
\text { your career as an engineer? }\end{array}$} \\
\hline Answer & Responses (n=81) \\
\hline Not at all & $0 \%(0)$ \\
\hline Somewhat helpful & $4.9 \%(4)$ \\
\hline Helpful but not crucial & $28.4 \%(23)$ \\
\hline Essential & $56.8 \%(46)$ \\
\hline Significantly advance career & $9.9 \%(8)$ \\
\hline
\end{tabular}

A third question was also intended to address the extent to which students thought of writing as an integral part of engineering work:

\begin{tabular}{|c|c|}
\hline \multicolumn{2}{|c|}{$\begin{array}{l}\text { To what extent do you think problem-solving skills in } \\
\text { communication are related to problem-solving skills in } \\
\text { engineering? }\end{array}$} \\
\hline Answer & Responses $(n=85)$ \\
\hline Not at all & $0 \%(0)$ \\
\hline Hardly related & $8.2 \%(7)$ \\
\hline Somewhat related & $25.9 \%(22)$ \\
\hline Closely related & $38.8 \%(33)$ \\
\hline Fully integrated & $27.1 \%(23)$ \\
\hline
\end{tabular}

Students were also asked questions that compared commitment in terms of time and effort to engineering and writing courses: 


\begin{tabular}{|l|c|}
\hline \multicolumn{2}{|l|}{$\begin{array}{l}\text { In terms of time, what priority do you assign to writing } \\
\text { courses compared to engineering courses? }\end{array}$} \\
\hline Answer & Responses (n=86) \\
\hline No priority & $1.2 \%(1)$ \\
\hline Low priority & $27.9 \%(24)$ \\
\hline Some priority & $53.5 \%(46)$ \\
\hline High priority & $17.4 \%(15)$ \\
\hline Greatest priority & $0 \%(0)$ \\
\hline
\end{tabular}

\begin{tabular}{|l|c|}
\hline \multicolumn{2}{|l|}{$\begin{array}{l}\text { In terms of effort, what priority do you assign to writing } \\
\text { courses compared to engineering courses? }\end{array}$} \\
\hline Answer & Responses (n=85) \\
\hline No priority & $2.4 \%(2)$ \\
\hline Low priority & $22.4 \%(19)$ \\
\hline Some priority & $47.1 \%(40)$ \\
\hline High priority & $27.1 \%(23)$ \\
\hline Greatest priority & $2.4 \%(2)$ \\
\hline
\end{tabular}

\section{4-2. Mid-term Evaluations}

Responses to the mid-term evaluations have not yet been analyzed for differences between team-taught and non-team-taught sections. Some issues are apparent from a preliminary review of student comments. In response to a question asking in what ways the course is or is not meeting their expectations, most students gave non-specific comments to the effect that it was meeting their expectations. Some, however, were critical:

- I expected both parts of the clinic to be related more. It seems we have two completely separate classes at times.

- I expected better coordination between this (writing section class) and the lab part.

- Thought it would be more connected to lab portion--more of an engineering thing than a writing thing.

Similar opinions were expressed, even more forcefully, in response to the question, What would you do to improve the course (50 words or less)? In this case, although formal comparisons have not been made, five of the eight comments below did come from nonteam-taught sections.

- Integrate it entirely with Sophomore Clinic I so that the only writing we need to do is the assignments we get from Clinic.

- I would count the lab as two credits and writing as two credits. We are trying to be engineers, not writers. Communication is important but not as much as clinic.

- The faculty should discuss projects openly so that the writing assignments will connect more directly to the lab portion of the course. 
- I would relate the two classes more. Our third paper seems to be the one and only link between the two.

- I think that the professors should meet (all at the same time) and discuss what will be covered the next week.

- Good course, but intertwine the lab with the writing section even more.

- Have more writing assignments dealing with an engineering topic.

- The two branches could be more intertwined.

When asked if they could see a clear connection between writing assignments and the lab portion of the course, students responded:

- Yes, they seem to be fitting together nicely. Writing about technical stuff that we do in lab and other classes is extremely good practice for real world situations.

- No. Except for Paper 3, I have no clue how the two are inter-related.

- To be honest, no. I would actually prefer that the writing course had nothing to do with engineering.

- Not really. Only the final client report hooks in between the lab and writing portion of the course.

- Yes, and I also see that the College Comp II version of this course is trying to let us write things that a true engineer would write.

- Not at first. The technical description is when the connection is starting to be made.

Finally, three comments in response to a question asking students to rate the overall quality of the course from 1 (low) to 10 (high) are worthy of note:

- I really don't like writing courses to begin with and this isn't much different than the rest.

- 4 , just because the engineering professional probably needs a good writing format less than $40 \%$ of the time but the lab is crucial.

- Where I work, letters and memos are drafted by the engineers, and actually written by the secretary. You should see the gibberish that my boss comes up with. But by the time the correspondence is sent out, the secretary makes it understandable. The engineer just makes sure that it's correct.

\section{4-3. Anecdotal Evidence}

The teaching logs kept by all faculty during the semester will provide a qualitative basis for interpretation of student comments. The teaching logs, though they may be fragmentary and certainly subjective, are the only available descriptive account of what actually happened during team-taught sessions. As such, it is hoped that they will shed light on what students may have observed and reacted to. Some representative anecdotes follow.

During one early session, students were brainstorming possible topics for their research papers. One area of interest was Mars exploration, as one of the two major Sophomore Clinic design projects concerned design of a mission to Mars. The 
engineering faculty member present has done work with NASA and was able to contribute a good deal of technical expertise to the discussion of potential issues. The ability to bring specific engineering knowledge to the writing classroom is certainly one of the more apparent benefits of team-teaching.

Another engineering faculty member observed that his most important contribution to the class was "quelling skepticism." At the beginning of the semester, he sensed that students did not think writing was important. During the semester, his impression improved because they seemed to acknowledge writing as a valuable skill. Yet "palpable skepticism" persisted about the value of the specific assignments being given. For example, students resisted an assignment to write a cover letter that went beyond conventional formalities and included descriptions of aptitudes, hobbies, and extracurricular activities. The engineering professor gave an example about the contents of his application materials, which had resulted in his being hired by Rowan. He told students about how he had described his avid interest in Shakespearean acting, and related it to skills needed for effective teaching. In another incident involving the same faculty member, students had some questions about how "real technical papers are written," which was an expression of resistance to certain standards that were being applied to their assignments. In response, he spent a few minutes going over the criteria reviewers use to evaluate publications. It was information they seemed to find interesting and, in his observation, they were more cooperative after the discussion.

A particularly intensive exchange occurred in one class meeting during a discussion of the challenges surrounding proposal writing. Students were required to submit a proposal of their research paper topic, complete with most of the major sections required in professional proposals. The writing faculty emphasized that the proposal would be taken as seriously as a professional proposal, in that approval constituted an investment of resources and promise of remuneration (in the form of a grade and credit, rather than funding) on the part of the instructor. During the class discussion, the engineering faculty member was instrumental in making clear the importance of proposal writing for their future careers, in that during employment (especially academic employment), proposals are very often written to government and industry to obtain funding for scientific research projects. He also helped support the writing instructor's emphasis on particular conventions and specifications by confirming that adhering to regulations on format and length was expected in the workplace and that not following the rules leads to automatic rejection. The importance of the one-page project summary was stressed as what captures the interest of any reviewer and motivates the reviewer to read on. Finally, he underscored the importance of an effective qualifications section, something the students saw as irrelevant in the context of the classroom, by testifying that the qualifications of the investigators are crucial in accepting or rejecting a proposal.

\section{Reflections on Preliminary Results}

The results of the initial survey show, as expected, that while engineering students acknowledge that writing is important in their field, they do not prioritize it and they tend to see it as secondary to "real" engineering work. They recognize that it is an important tool, but do not necessarily believe that writing skills directly enhance engineering skills-- 
that is, that being a better writer means not only that one's ideas will be more clearly communicated, but that those ideas will be better in the first place.

The results of the midterm evaluation clearly point out that inconsistent integration of the two components of the course remains a problem. Many students, at least at that point in the semester, continue to perceive the course as divided and continue to resent what they see as a double workload. The results are uneven, though, in that some students remarked, on the contrary, that they were impressed with the degree to which the writing course had been built into the engineering course.

The anecdotal evidence is perhaps the bright spot in these preliminary findings. Faculty definitely found the teaching environment to be enriched by the presence of both writing and engineering faculty. A number of interesting "teaching moments" occurred that could likely only be produced through the interactive discussions happening between the faculty. Much of this took the form of the engineering faculty confirming what the writing faculty were saying, even though the team-teaching project was specifically framed as being a collaborative effort that would strictly avoid issues of teacher authority. It will be very interesting to see what students have to say about this.

Ideally, the most desirable outcome of this semester's version of Sophomore Engineering Clinic I would be a discernible inability to separate writing from engineering. We would like to hear students say that prioritizing engineering work goes hand-in-hand with prioritizing writing. The combination of a more integrated course design and more overt teaching collaboration will hopefully convey the message that much of engineering is writing. Future investigations will focus more closely on the "mechanisms" of teaching collaboration--what relationships and interactions come into being in the classroom and what effects they have on student learning. In particular, assessment methods, perhaps both qualitative and quantitative, that can elicit student perceptions of the classroom environment are needed. As previous studies have suggested, authority and disciplinary practices are among the issues at stake when faculty from different disciplines collaborate on writing instruction. Team-teaching in all its forms should continue to provide rich ground for exploring the relationship of writing to specific disciplines such as engineering.

\section{References}

1. J. Newell, A. J. Marchese, R. P. Ramachandran, B. Sukumaran, and R. Harvey, "Multidisciplinary design and communication: A pedagogical vision," International Journal of Engineering Education, Vol. 15, 1999.

2. R. Harvey, F. S. Johnson, A. J. Marchese, J. Mariappan, R. P. Ramachandran, B. Sukamaran and J. Newell. "Teaching Quality: An Integrated TQM Approach to Technical Communication and Engineering Design." Proceedings of the American Society of Engineering Education: Mid Atlantic Conference, April 17, 1999.

3. F. S. Johnson, "Negotiating a Rhetorical Education: Teaching Technical Writing and Argumentative Discourse to Engineering Students," Penn State Conference on Rhetoric and Composition, July 1999. 
4. J. R. Davis, Interdisciplinary Courses and Team Teaching: New Arrangements for Learning. Phoenix: The American Council on Education and The Orynx Press, 1995.

5. R. Harvey, "Beyond missionaries, colonists, and English department imperialism: WAC as dual citizenship," Midwest Modern Language Association, 1994.

6. R. Harvey, Engineers and English teachers: a case study of writing instruction in a chemical engineering course, unpublished master's thesis, University of North Dakota, 1991.

7. D. Ludlow and K. Schulz, "Writing across the engineering curriculum at the University of North Dakota," Journal of Engineering Education Vol. 82, 1994.

\section{Biographical Sketches}

Roberta Harvey is an Instructor in the College Writing Department at Rowan University and has been teaching writing to engineering students since 1992. She is completing work towards a doctorate in Composition and Rhetoric from the University of Wisconsin at Milwaukee.

Frances Swigon Johnson is an Assistant Professor in the College Writing Department at Rowan University. She has been teaching technical writing since 1989, formerly at Old Dominion University and the University of Oklahoma, and came to Rowan in 1996. She holds a Ph.D. in English with a specialization in Composition, Rhetoric, and Literary Studies from the University of Oklahoma, Norman.

Heidi L. Newell received her Ph.D. from the University of North Dakota and is now serving as a consult to Rowan with respect to ABET accreditation. She has prior experience on ABET accreditation at the University of North Dakota.

Kevin Dahm is an Assistant Professor of Chemical Engineering at Rowan University. He received his Ph.D. from the Massachusetts Institute of Technology (MIT) in 1998. Prior to joining Rowan, Kevin was a postdoctoral fellow at the University of California at Berkeley and an adjunct faculty member at North Carolina A\&T University.

Anthony J. Marchese is an Assistant Professor in the Department of Mechanical Engineering at Rowan University. He received his Ph.D. from Princeton University in 1996. In 1999, he was awarded a Leadership Development Internship from ASME to serve on the ASME Council on Education.

Ravi P. Ramachandran is an Associate Professor in the Department of Electrical and Computer Engineering at Rowan University. He received his Ph.D. from McGill University in 1990 and worked at AT\&T Bell Laboratories and Rutgers University prior to coming to Rowan.

John L. Schmalzel is the Chair of Electrical and Computer Engineering at Rowan University. He received his Ph.D. degree in 1980 from Kansas State University. He was on the faculty at the University of Texas at San Antonio prior to joining Rowan. 
Carlos Sun is an Assistant Professor of Civil and Environmental Engineering at Rowan University. He received his Ph.D. from the University of California at Irvine in 1998. Prior to joining Rowan, he worked at California Path.

Paris Von Lockette is an Assistant Professor of Mechanical Engineering at Rowan University. He received his Ph.D. from the University of Michigan, Ann Arbor, in 1999. 